\title{
Plastic in the Food Chain and the Expected Pandemic of Cancer?
}

\section{ISSN: 2637-773X}

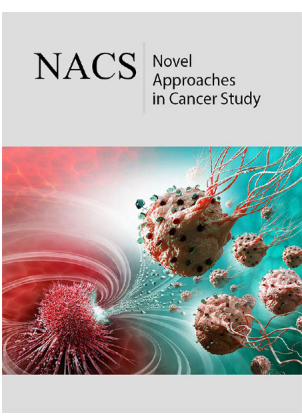

*Corresponding author: Vincent van Ginneken, Blue green technologies, Bart Crumstraat 18-12, 6866 AC, Heelsum, Netherlands

Submission: 鰃 September 23, 2019

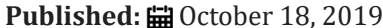

Volume 3 - Issue 3

How to cite this article: Vincent van Ginneken. Plastic in the Food Chain and the Expected Pandemic of Cancer?. Nov Appro in Can Study. 3(3). NACS.000564.2019. DOI: 10.31031/NACS.2019.03.000564

Copyright@ Vincent van Ginneken, This article is distributed under the terms of the Creative Commons Attribution 4.0 International License, which permits unrestricted use and redistribution provided that the original author and source are credited.

\section{Vincent van Ginneken*}

Blue green technologies, Heelsum, Netherlands

\section{Introduction}

The world has a persistent plastic pollution problem and despite tremendously societal awareness we state the efforts of the International Scientific Community (ISC) are heavily lagging behind politics and other organizations, which we will substantiate further. On October 12, 2018, President Trump called out other nations, including China and Japan, for "making our oceans into their landfills" when he signed a legislation to improve efforts to clean up plastic trash from the world's oceans [1]. Also, The European Parliament voted positively October 26, 2018 to approve a measure to ban single-use plastic across the continent which assignment hopefully could be enforced as early as 2021 [1]. This may be the first time in human history concerning ecological problems that politics and social media are at the forefront and the ISC is lagging behind. The accumulation of plastic waste in the oceans is a global, rapidly growing problem. Especially in recent years, much attention has been paid to curb the ongoing flow of plastics and the toxic chemicals they contain into the marine environment. While the world's population now produces roughly its own weight in plastics per year, which is around 360 billion kilos/year in 2018 with a projection of 500 billion kilos/year in 2025. In addition, it is estimated that more than 280,000 tons of plastic float in the world-oceans. Experts are particularly concerned about the enormous amounts of plastic nanoparticles -estimated by [2] at a minimum of 5.25 trillion particles weighing 268,940 tons- that are smaller than grains of sand ( 0.1 microns or less) and are a life-threatening situation. We have indications that plastic pollution is a new ecological problem and ultimately can cause a global increase of cancer cases. The suggested mechanism is the following. The Humboldt Current eastern gyre ecosystem is a highly productive ecosystem. It is the most productive eastern boundary current system. It accounts for roughly $18-20 \%$ of the total worldwide marine fish catch. The species are mostly pelagic: sardines, anchovies and jack mackerel. Fish meal is usually made from these cheap pelagic fish species. We hypothesize plastic accumulates in the global five oceanic gyre systems (Figure 1; courtesy 5gyres.org) including the ecological very productive Humboldt Current eastern gyre ecosystem.

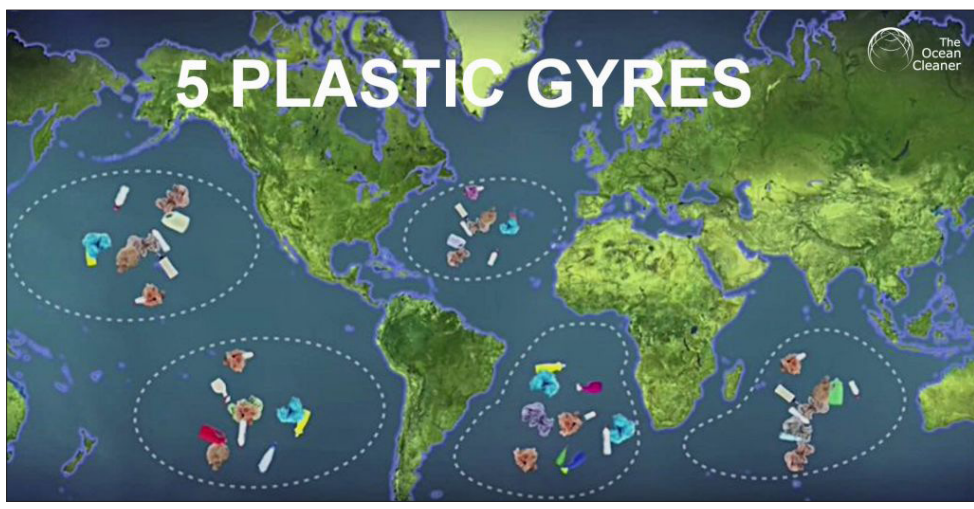

Figure 1: Plastic waste accumulating in our five ocean gyre systems including the very ecological productive Humboldt Currest eastern gyre ecosystem production chamber of mostly pelagic fish species like sardines, anchovies and jack mackerel which are processed in the fish meal industry in this way contaminating our feed-casu quo food-chain with plastic and plastic nano-particles (courtesy image: 5gyres.org). 
In this way plastic nanoparticles can enter the human food chain via fishmeal which is used in animal feed for growing pigs, chickens and fish in aquaculture (animal husbandry =>"feed") and finally "food" for human consumption. This fish meal is usually made from cheap pelagic fish such as herring and anchovy fish (Figure 2).

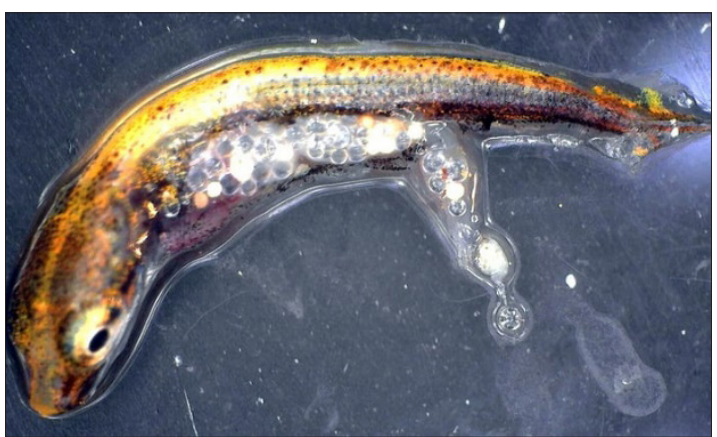

Figure 2: Plastic nanoparticles accumulated in pelagic fish used for fish meal in this way are plastic nanoparticles entering our food chain.

That the ISC is largely behind the social and political base of plastic pollution in the ocean and the risk of the very threatening contamination of our food chain may be apparent from the appearance of only two serious reviews in the past two years related to this topic $[3,4]$. To the best of our knowledge, these critical comprehensive reviews are the sole research efforts that the ISC has made at this moment to tackle this urgent and compelling ecological problem with far reaching medical consequences and many factors to study. Moreover, the plastic nanoparticles contain all types of chemical additives such as harmful PCB-like substances and pseudo-estrogens that in this way penetrate directly into the food chain of humans and animals. These plastic nanoparticles -ubiquitous in all marine compartments- can cause chronic degenerative inflammatory westernized welfare diseases (CDWDs) such as type- 2 diabetes, cardiovascular diseases and cancer, by penetrating human blood stream and even cells [5,6]. Like other particles, such as air pollution, they can cause inflammation, an immune response to anything that is recognized as "foreign" to the body, which can also cause diseases such as cancer; think of lung cancer by asbestos. Another potential concern is that plastic nanoparticles can become carriers for other toxins to enter the body and act as endocrine disruptors (EDCs). For example, nanoparticles can bind in the ocean water to compounds containing toxic carcinogenic heavy metals, such as mercury, arsenic and lead and organic pollutants such as some pesticides and chemicals like dioxins that are known to cause cancer and cause reproductive and development problems. When the nanoparticles enter the body, these toxins can accumulate in adipose tissue. The majority of cancers (estimated at $80 \%$ ) are related to a High-Fat diet and obesity [7] (Figure 3).

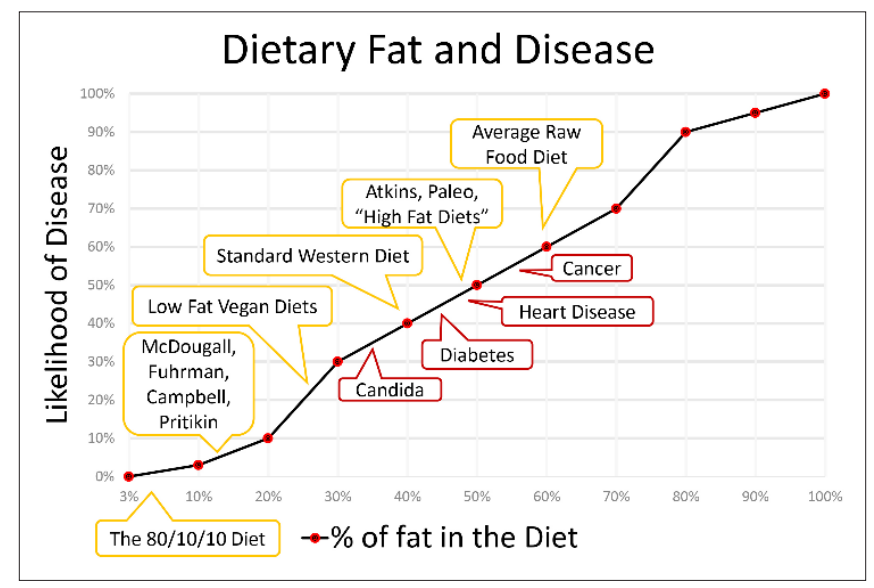

Figure 3: Correlation of our westernized welfare diseases and a High-Fat diet. Plastic nanoparticles can via fishmeal (feed) fed to cattle \& fish finally enter our human food chain causing Chronic Degenerative Welfare Diseases like type-2 diabetes, cardiovascular diseases and cancer (Source modified [5]).

It cannot be denied cancer remains a leading cause of death worldwide. First some facts before we give our comments:

A. Around $10 \%-20 \%$ of the cancers have a genetic predisposition while the other $80 \%$ are mainly caused by environmental factors $[5,6]$.
B. For decades it was already known that unhealthy food, a sedentary lifestyle and smoking were possible causes for cancer [6].

C. About $41 \%$ of the Americans will develop cancer (including nonmelanoma skin cancer) in their lifetime and 1/5 of the Americans will die from cancer [7]. 
D. Now seven years later after the heated discussion or environmental factors may cause cancer $[8,9]$ to be conditioned by new scientific insights regarding organic contaminants - especially plastics - and the substances they contain such as plasticizers, pseudo-estrogens and polychlorinated biphenyls (PCBs)- we want to take as a starting point that Science lags behind in studying the effects of plastic nanoparticles in the environment and the development of cancer through the food chain.

E. A very recent study by the IARC workgroup in the NEJM study definitely proved, based on more than 1000 epidemiologic studies that obesity is directly correlated to several types of cancer [7]. A safe option is the replacement of fishmeal by meal made from "clean" insect mealworms, which can digest the thick cell wall of seaweeds, like the green Atlantic seaweed sea lettuce or Norwegian Kelp [10]. Another possibility to reduce the risk for cancer is that standardized protocols should be developed -based on Raman Spectroscopy combined with Microscopy- to isolate and detect microplastics of $\approx 1-2 \mathrm{~mm}$ in caught pelagic fish used for fishmeal [3]. These strategies are from (eco)-toxicological point of view of interest for human health of the whole society with the danger of plastic poisoning lurking.

\section{Acknowledgment}

The author thanks the new board of Bluegreentechnologies for the financial means to make publication of this manuscript possible.

\section{References}

1. Howard BC (2018). Planet plastic. National Geographic.

2. Eriksen M, Lebreton LC, Carson HS, Thiel M, Moore CJ, et al. (2014) Plastic pollution in the world's oceans: More than 5 trillion plastic pieces weighing over 250,000 tons afloat at sea. PloS one 9(12): e111913.

3. Lusher AL, Welden NA, Sobrai P, Cole M (2017) Sampling, isolating and identifying microplastics ingested by fish and invertebrates. Anal Methods 9: 1346-1360.

4. Smith M, Love DC, Rochman CM, Neff RA (2018) Microplastics in seafood and the implications for Human Health. Curr Envir Health Reports 5(3): 375-386.

5. Christiani DC (2011) Combating environmental causes of cancer. N Engl J Med 364(9): 791-793.

6. Dark Graham G (2013) Oncology at a Glance, ISBN 978-1-118-36969-2, John Wiley \& Sons LTD, New Jersey, USA, p.132.

7. Lauby-Secretan B, Scoccianti C, Loomis D, Grosse Y, Bianchini F, et al. (2016) Body fatness and cancer-viewpoint of the IARC working group. $\mathrm{N}$ Engl J Med 375: 794-798.

8. Willett WC, Colditz GA, Hiatt RA (2011) Combating environmental causes of cancer. N Engl J Med 364 (23): 2266.

9. Tarone RE, McLaughlin JK (2011) Combating environmental causes of cancer. N Engl J Med 364(23): 2266-2267.

10. Nederlof MAJ, Durif CME, Verdegem MCJ, Booms R, de Vries E, et al. (2017). Giant mealworm (Zophobar Morio) as a "vehicle" to transport healthy nutritional ingredient from seaweed (Ascophyllum nodosum) towards fish cultured: Amino acids. Journal of Advances in Agriculture Science and Technology 4(5): 1-13. 